\title{
Using spatial models of temporal tree dynamics to evaluate the implementation of EU afforestation policies in rangelands of SW Spain
}

\author{
E. Herguido Sevillano, J.F. Lavado Contador, S. Schnabel, M. Pulido, J. Ibáñez
}

\begin{abstract}
A B S T R A C T
Iberian silvopastoral systems known as dehesas in Spain and montados in Portugal are undergoing a spatially polarized process by which many of the main areas lack tree recruitment, whereas marginal lands suffer abandonment and shrub encroachment. These ongoing processes should be considered when designing afforestation measures and policies. We analyzed the temporal tree dynamics in 800 randomly selected plots of $100 \mathrm{~m}$ radius in dehesas and treeless pasturelands of Extremadura by comparing aerial images taken in 1956 and 2012. Based on this data, spatial models that predict areas prone to undergo or lack natural tree recruitment were developed using three data mining algorithms: MARS (Multivariate Adaptive Regression Splines), Random Forest (RF) and Stochastic Gradient Boosting (TreeNet, TN). A number of 51 candidate environmental, physical and land use and cover spatial variables were used as predictors in models, from which the main 15 were selected. The statistical models developed were deployed to the spatial context of the rangelands in Extremadura and, separately, to the afforested areas performed under the UE First Afforestation of Agricultural Land program between 1992 and 2013. The percentage of area predicted as prone to tree recruitment was calculated in each case. The three data mining algorithms used showed high fitness and low misclassification rates. Although the drivers and patterns of the different models were similar, outstanding differences were observed among models attending the area prone to tree recruitment. A model ensemble was also produced as a map of agreement reflecting the majority vote among models. Despite these differences, when maps of the model results were related to the afforested surfaces, the three algorithms pointed to the similar conclusion, i.e., the afforestations performed in the studied rangelands barely discriminated between areas that already showed or lacked natural tree regeneration. In conclusion, data mining technics are suitable to develop high-performance spatial models of vegetation dynamics. These models are useful to help policy design, decision-making and assessment about the implementation of afforestation measures and could be used to improve the spatial targeting of future programs.
\end{abstract}

\section{Introduction}

Spain, with 5.6 million ha, is the European country with the largest agroforestry surface, of which 217,000 ha are classified as High Nature Value Farming areas (den Herder et al., 2017). Dehesas in Spain and montados in Portugal belong to these systems. They are characterized by the presence of scattered trees, mainly Holm oak (Quercus ilex subs. ballota (Desf.) L.) and Cork oak (Quercus suber L.), with seasonal grasslands and a diversity of shrub species. These shrubs have a variable density mainly depending on the intensity of land use and the management characteristics. In Extremadura, located in Southwest Spain, dehesas occupy vast surfaces and play an important role in the local economy and culture (Diaz et al., 1997).

As other agroforestry systems around the world (Gibbons et al.,
2008), dehesas and montados are experiencing the lack of tree recruitment and face a deforestation risk (Costa et al., 2014; Moreno and Pulido, 2009). They are suspected to show inherent problems for tree recruitment (Plieninger et al., 2003; Pulido et al., 2001), that are worsening due to the socioeconomic and land management transformations occurred during the last decades, as those leading to the end of the transhumance and to the increase of the livestock rates (Carmona et al., 2013; López-Sánchez et al., 2016). Moreover, these transformations seems to be spatially polarized, with the more profitable and manageable lands being intensified in land use, while the marginal areas are abandoned and experience shrub encroachment (Godinho et al., 2014; Herguido et al., 2017). Those coexisting processes lead to a net loss of outstanding surface amounts of dehesas and montados.

To restore degraded areas and favor the forest re-establishment, 


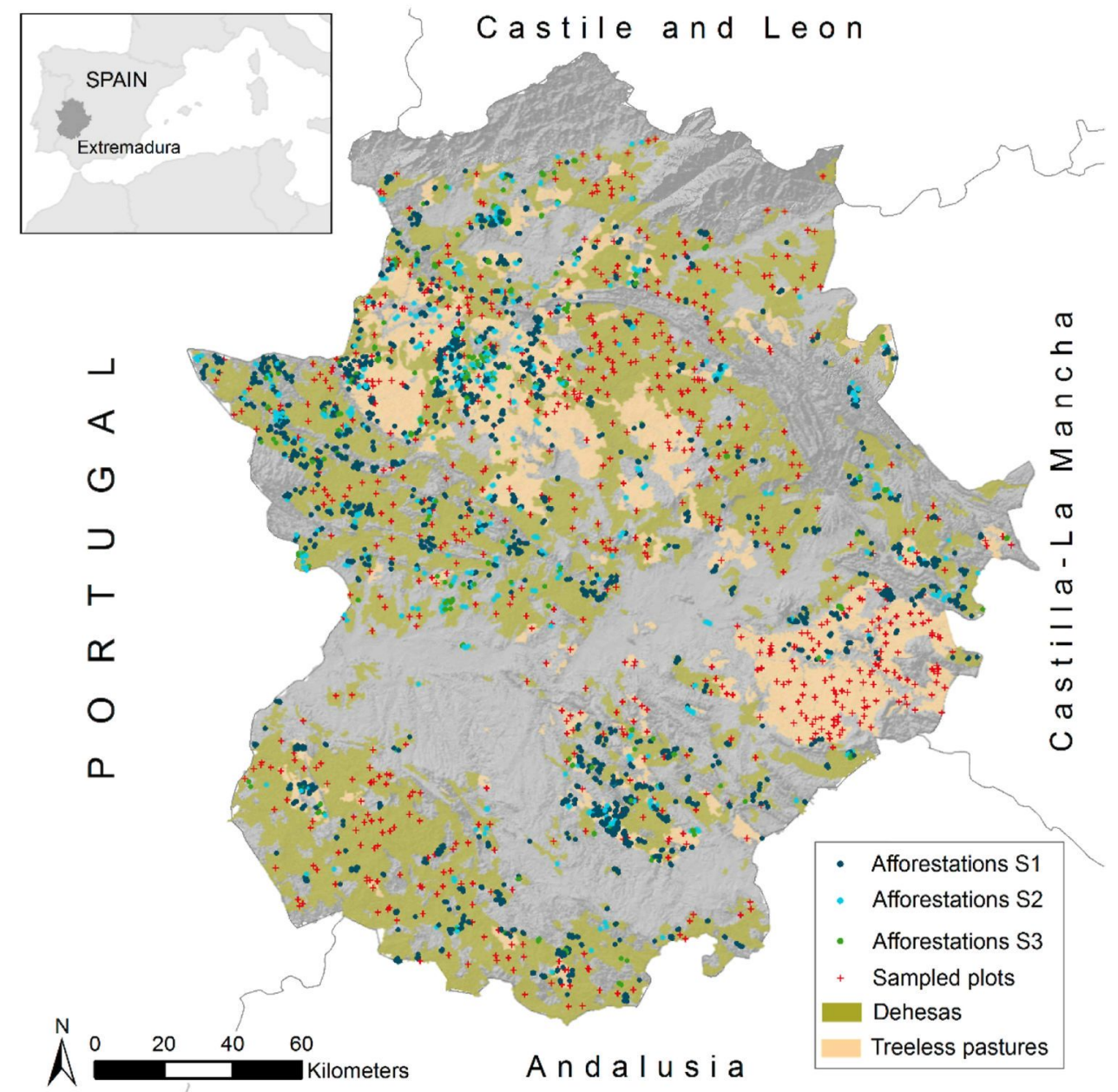

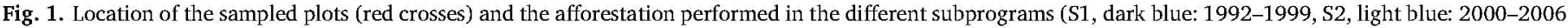
and S3, light green: 2007-2013) of the EU First Afforestation of Agricultural Land program in the rangelands of Extremadura.

afforestation and reforestation measures have often been used. In the last 150 years, Spain undergone several large-scale programs in which more than 5 million hectares (approximately 10\% of the country area) were afforested or reforested (Vadell et al., 2016). Through time, not only the characteristics, species and techniques used in these afforestations changed, but also the main underlying socio-economic and political contexts. In the period between the 1940 s and the 1980 s, reforestations were mainly done on public lands with autochthonous and exotic Eucalyptus and Pinus species, generally planted as monospecific stands (Ruiz et al., 2008; Toval, 1999). Among the objectives of these reforestations were soil protection, forest restoration and timber production, but also the improving of the economy of the rural areas.

After Spain joined the European Economic Community (EEC) in 1986 and the implementation of the Common Agricultural Policy (CAP), there was an important shift of forest plans. New techniques were used during this period to improve the success of seedlings and decrease the impact on soils. The Afforestation of Agricultural Land program (EEC regulation 2080/92), was particularly relevant and offered EU funds for afforesting on private lands. Other aids provided by the European Agricultural Fund for Rural Development (EAFRD) have been devoted to tree densification, as the agri-environmental measures for the sustainable management of forest.

of all, the First Afforestation of Agricultural Land program was particularly relevant, being applied trough three subprograms in different periods: 1992-1999, 2000-2006 and 2007-2013. These actions were mainly targeted to retire marginal agricultural lands from exploitation with the objective of reducing agricultural products surpluses
(Campos et al., 2003). Afforestations performed under this program used a variety of autochthonous species, being Holm oak the most common one, planted preferably in mixed stands (Vadell et al., 2016). Subsidies along the first two subprograms covered $100 \%$ of plantation costs, and only amounted to $70-80 \%$ during the third. The program also covered maintenance expenses and the reposition of dead seedlings or saplings during five years. Besides, landowners receive an annual money amount per hectare, aimed at compensate profit losses related to the prohibition of cropping and ranching in the afforested lands during 15-20 years. This program considered dehesas as suitable for afforestation, provided certain criteria was met. During the first subprogram, dehesas should show less than $20 \%$ of tree canopy cover. In the second one, they were required to present less than 10 trees/ha or 20 juvenile trees/ha. The third period only considered those dehesas with less than $5 \%$ of canopy cover or less than 10 trees/ha or 20 juvenile trees/ha. Besides, for the two lasts periods, candidate dehesas should also lack abundant and viable natural tree recruitment.

On the whole, the first afforestation of agricultural land program increased oak woodlands and decreased cereal production in the 1990s. Since then, participation has dropped off as a consequence of changes in subsidies regulations (Sánchez-González et al., 2015). Due to the lack of exhaustive and sustained monitoring programs, data on the long-term success of those plans is very scarce (Sánchez-González et al., 2015).

In general, forecasting land use and cover changes and its impacts can help to better inform policy decisions (Verburg et al., 2006). In this regard, data mining techniques are suitable to develop high-performance spatial models of vegetation dynamics (Herguido et al., 2017; 
Zaragozí et al., 2012). These models have a potential application in helping to identify adequate locations for the implementation of environmental programs, thus improving the spatial targeting processes and hence their cost-effectiveness (Uthes et al., 2010).

The main aim of this work is to assess the extent to which afforestations carried out in Extremadura under the 1992-2013 EU Afforestation of Agricultural Land program took into account the land likelihood to undergo natural tree regeneration as a main land condition to qualify for afforestation subsidies. With this purpose, data mining techniques were used to build spatial models that predict the areas prone to either present or lack natural tree recruitment in the Extremenian dehesas and pasturelands. Models were trained with data obtained from the observed presence or lack of tree recruitment between 1951 and 2012 in the study areas, using as predictive variables a set of spatialized physical and socio-economic ones. Model results were afterward analyzed and the maps obtained compared to the areas afforested between 1992 and 2013.

The method used and the results could be of interest when designing future programs devoted to improve tree density or the forested surfaces, since taking the spatial information into account would help focused efforts where they are more needed.

\section{Material and methods}

\subsection{Study area}

The study area corresponded to the whole surface covered by dehesas and treeless pasturelands in Extremadura (SW Spain), henceforth rangelands (Fig. 1) (data obtained from the Montado/Dehesa project of the European Territorial Co-operation program INTERREG III-A). While data are not consistent among authors, dehesas cover approximately $1,400,000$ ha in the region, with treeless pasturelands covering approximately 600,000 ha. Both types of rangelands are mainly grazed by sheep and cattle, being pigs also important in wooded dehesas. The size of the farms is highly variable and most of them are on private ownership, but also farms of communal use, owned by the municipalities, are frequent.

It should be noted that some of the treeless pasturelands considered as study areas in this work would not legally qualify as subject to afforestation because they constitute protected areas of the Natura 2000 network. Nevertheless, the study was extended to them in order to better characterize tree recruitment processes and to feed the models with more accurate spatial data.

Altitude varies between $200-400 \mathrm{~m}$ in the study area and the topography is gently undulated, geologically consisting in old erosion surfaces formed over Precambrian shales and greywackes intersected by river valleys that present the steepest slopes (Gómez Gómez Amelia, 1985; Schnabel et al., 2013). Soils are poor in nutrients and organic matter and show a low potential for agriculture, being most of them shallow, slightly acid and sandy to silty loam textured (Pulido and Picardo, 2010). Climate is typically Mediterranean with continental and oceanic influence; it is characterized by warm, dry summers and wet, mild winters. Annual precipitation varies between 500 and $750 \mathrm{~mm}$, mainly concentrated in spring, winter and autumn. The mean annual temperature range between $15-17^{\circ} \mathrm{C}$.

\subsection{Deternination of the temporal tree dynamics and afforested sites}

During the period from 1956 to 2012, the persisting, lost and new trees where precisely located in 800 sampled plots randomly distributed over the studied rangelands (Fig. 1), avoiding all the afforested areas. Afforested areas are easily identifiable with the aerials images, as the land is first cleared and tilled, and then, the trees are planted in a regular spatial pattern. The plots are circles of $100 \mathrm{~m}$ radius that cover a total area of 2510 ha. Tree changes occurred along time were identified by comparing orthorectified aerial photographs from 1956 with infrared images taken in 2012 (Spatial Data Infrastructure of Extremadura (IDEE), http://www.ideextremadura.es/Geoportal/).

Furthermore, data records were also gathered about the actions performed in the region between 1992 and 2013 corresponding to the First Afforestation of Agricultural Land program. As the provided data were alphanumeric records, a map was generated by spatially matching the records with the georeferenced polygons obtained from the Spanish Geographic Information System of Agricultural Plots (SIGPAC, Spanish Ministry of Agriculture, Fishery, Food and Environment). Afforestation locations belonging to the three operative subprograms (S1: 1992-1999, S2: 2000-2006 and S3: 2007-2013) are showed in Fig. 1.

In order to guarantee that the area enclosed by the georeferenced polygons were completely afforested, a spatial assessment of their accuracy was performed by randomly selecting $10 \%$ of the plots from each subprogram. The selected plots were visually inspected by comparing the area covered by the SIGPAC polygons with the information observed in images from 1986, 2006 and 2012, all of them obtained from the IDEE. When the polygons did not correspond to true afforestations, they were given a different code. In case that one afforestation did not cover the whole area of the corresponding polygon, the non-afforested surface was manually digitized and a different code was given to each polygon part according with its condition, i.e. afforested or delineation error (Fig. 2).

\subsection{Modelling the proneness to undergo natural tree recruitment}

Due to their powerful nonlinear modelling capabilities, data mining and machine learning techniques have proven to be useful in disentangling complex environmental relationships, particularly for predictive modelling and mapping. Among those techniques, Random Forest, Multiadaptive Regression Splines (MARS ${ }^{\circ}$ ) and Stochastic Gradient Boosting constitute powerful statistical algorithms that have been already used to build spatial models, as those predicting the areas likely to present or lack tree recruitment (Herguido et al., 2017). These three techniques are non-parametric approaches to build classification models. MARS seek to model nonlinearities and interactions between variables in a form of non-parametric logistic regression analysis. Random Forests and Stochastic Gradient Boosting represent variations of the Classification and Regression Trees (CART ${ }^{6}$ ) algorithm that seek to improve model predictions by combining multiple separate classification trees in an ensemble of them in different ways.

Briefly stated, a MARS model begins by approximating the response with a constant $\left(y=\beta_{0}\right)$ and calculate a series of piecewise or Basis Functions (BF's), which produces the best fit in the model. Interactions were allowed among variables at a second degree. The main MARS algorithm is (Friedman, 1991):

$y=f(x)=\beta_{0}+\sum_{m-1}^{M} \beta_{m} h_{m}(x)$

Being: $y$ the value predicted by the model by means of a function $f$ $(x)$, which can be decomposed into an initial constant $\beta_{O}$ and a sum of $\mathrm{M}$ terms, each of them being formed by a coefficient $\beta_{\mathrm{m}}$ and a basis function $h_{m}(x)$.

As MARS, TreeNet ${ }^{\text {ma }}$ stochastic gradient boosting (TN) (Friedman, 1991 ) is a machine learning technique considered here to solve classification problems. In this case, it produces very small CART trees and combines them into a powerful model in the form of an ensemble of weak prediction decision-tree models (settled to 1000 in the study). It builds the model in a stage-wise fashion and generalizes by the optimization of a loss or cost function. At each algorithm iteration, a base learner is fitted on a subsample of the training data set drawn at random without replacement.

Finally, Random Forests (RF) (Breiman, 2001) is also used for classification by constructing a multitude of decision trees during the training process (settled to 1000 in the study) and outputting the class 


\section{a) 2005}

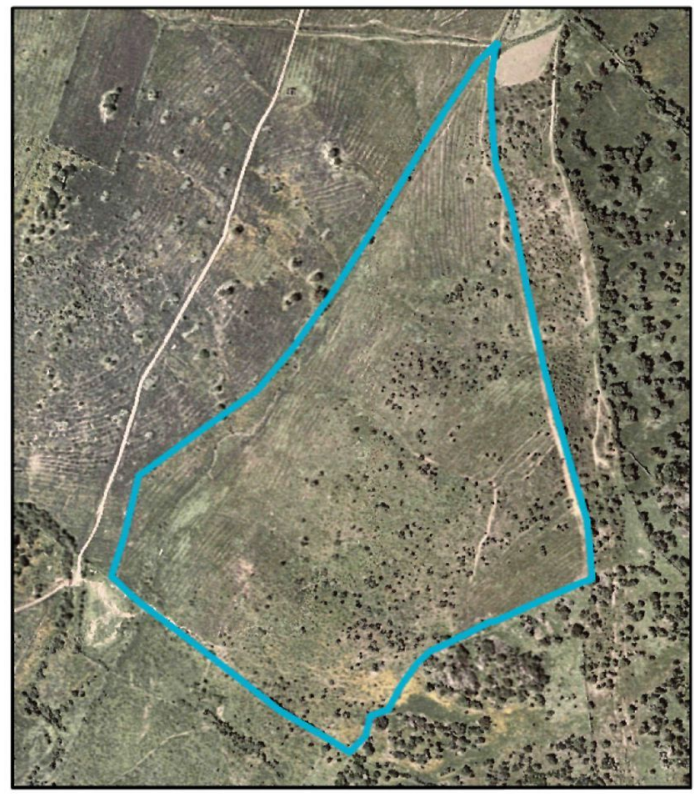

b) 2012

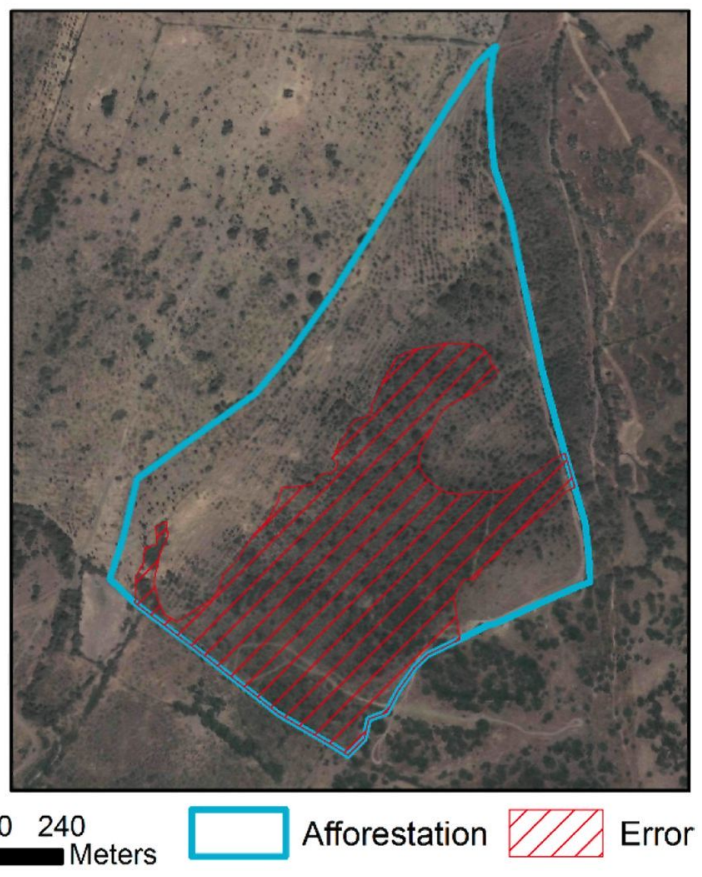

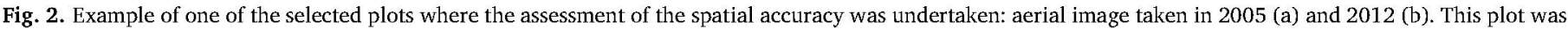
not completely afforested and the delineation area error is highlighted with a red hatch.

that is the mode of those predicted by the individual trees. Random decision forests correct for decision trees' trend to be over-fitted to the training set.

In each model, two classes that reflect the likeliness of a place to undergo tree recruitment or not were assigned to each piece of land based on a balanced threshold value provided by the three model algorithms.

Combining multiple model outcomes in a model ensemble frequently provide more accurate results than the best of its components (Seni and Elder, 2010). In the study, an additional model ensemble was generated in the form of a map of agreement. To do it, model outcomes generated using each of the algorithms were combined in a map where the predicted categories were assigned based on the majority vote among models, i.e., a location was predicted as prone to tree recruitment when two or more of the models predicted it as such, and conversely for the not-recruitment locations (Fig. 3). This map of agreement is considered here as relevant, particularly when a final map is needed that must encompass the slightly different, while reliable, spatial patterns obtained with different techniques. Salford Predictive Modeler (SPM 8.0) software was used for data mining statistical analysis and ArcGis 10.2 for the mapping purposes.

\subsubsection{Model settings: the dependent variable}

Recruited-tree locations (1) vs. places of no recruitment (0), which were randomly selected in the sampled areas, constituted the binary dependent variable. The number of recruited trees in the sampled areas amounted to 16,551. Correspondently, the same number of locations of no recruitment were randomly selected in the sampled areas. No recruitment places met the premise of being located at least $15 \mathrm{~m}$ beyond any place of a recruited tree. This buffer distance was chosen in order to exceed the aggregation pattern distance of recruited trees, which corresponded to $10 \mathrm{~m}$ and was calculated as follows: 25 plots containing at least 10 recruited trees were randomly selected from the total set of sampled plots. Afterward, a Ripley's L tests was computed independently for each one and the confidence intervals calculated by performing 99 Monte Carlo simulations. Finally, the average of all those functions was calculated. Recruited trees were found to be randomly distributed at a distance greater than $10 \mathrm{~m}$, from which they showed to be spatially clustered. The spatial pattern analysis described was performed using Spatstat package (Baddeley et al., 2015; Baddeley and Turner, 2005) in R 3.2.3. (R R. Core Team, 2015).

From the whole dataset (points with or without tree recruitment), $95 \%(31,447$ points) of data was segregated to train and test the spatial models. From this, the $75 \%(23,585$ points $)$ was used to train the models, and the $25 \%$ (7862 points) to test their fitness. The remaining $5 \%$ of data (1655 points) from the whole dataset was used as a further test set used to validate the model ensemble. Model fitness was assessed by calculating the Area Under the Receiver Operating Characteristic Curve (ROC AUC) and the misclassification rates over the $25 \%$ and $5 \%$ test datasets.

\subsubsection{Model settings: predictive variables}

Considering the availability for the whole study area and the likely relationships to the spatiotemporal dynamics of trees, a variety of explaining variables, amounting to 48 , were first preselected as candidates for modelling (table S.1). As topographic variables, elevation, slope, aspect, curvature (general, profile and planform curvature; Zevenbergen and Thorne, 1987), the standardized topographic position index (TPI) (Weiss, 2001) and the topographic wetness index (TWI) (Beven and Kirkby, 1979) were computed from a $5 \mathrm{~m}$ mesh size digital elevation model (DEM) of the study area. Several climatic variables were also considered, i.e. the potential evapotranspiration, as obtained from the CGIAR-CSI Global-Aridity and Global-PET Database (Zomer et al., 2007, 2008), and 19 bioclimatic variables (Hijmans et al., 2005) from http://www.worldclim.org, all with an spatial resolution of approximately $1 \mathrm{~km} 2$. Soil type classes (modified from the Provincial Soil Maps of Spain 1:250,000) and the parent rock class (Geologic Map of Spain 1:1,000,000) were used as predictive variables as well. Furthermore, as variables depicting vegetation cover, the percentage of tree canopy cover and the total vegetation cover in 2006 (obtained from the Forest Map of Spain 1:50,000), along with the shrub cover in 2005 (obtained from the Land Use Information System of Spain, SIOSE 1:25,000) were used. Distances (euclidean distance) to roads, urban areas and rivers were calculated from the Spanish National 

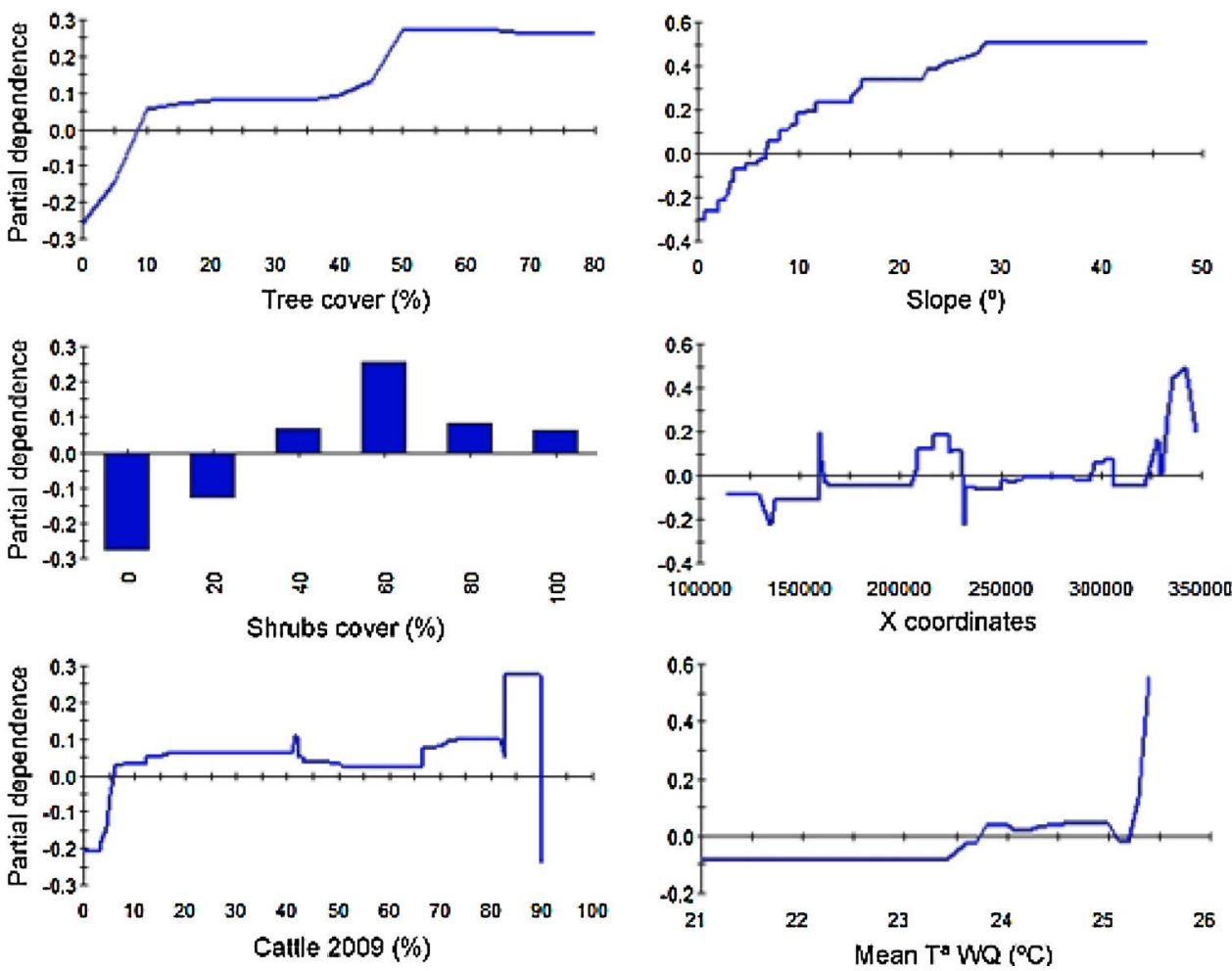

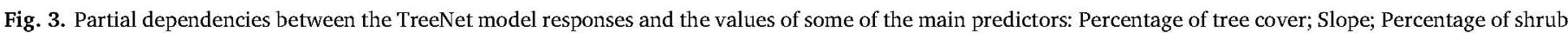
cover; Latitude (X) coordinate; Percentage of cattle in the per-municipality AU, Mean temperature of the warmest quarter.

Cartographic Base $(1: 200,000)$ and considered as candidate variables, since these are frequently related with vegetation patterns. Additionally, obtained from the Spanish National Statistical Institute (INE), some demographic and socioeconomic variables were considered as potentially explaining the spatiotemporal tree dynamic, i.e., the 1999 and 2009 cattle equivalent Animal Units (AU) at municipality level, the percentage of AU corresponding to cattle, the municipal population density in 1991, 2000 and 2006, the percentage of people older than 65 years in 1991, 2000 and 2006, the unemployment rate in 2009 and the population growth rate between 1991 and 2009. Collinearity is probably not detrimental for the reliability of the models with the algorithms used (Dormann et al., 2013), even when it is expected and there is spatial autocorrelation among variables (Herguido et al., 2017). Longitude and latitude geographical coordinates of the trees were included as variables to account for the influence of possible geographical relationships.

At a fist stage in modelling and to reduce model complexity, the 15 more important variables were selected among all by applying the automate GLM (TN-GLM) method (https://www.salford-systems.com// 35-what-s-new-in-spm-v8), as specified in SPM 8.0. With this procedure, an initial TreeNet model is generated intended to arrange a revised list of variables that include only the main predictors. The variables therefore selected in order of relative importance are showed in Table 3. Afterwards, the TreeNet, Random Forest and MARS models were settled and run using these selected variables. For MARS, a penalty value of 0.01 was settled to added variables in the model and a second degree of interaction was allowed to a maximum of 160 basis functions. For the main explanatory variables, graphs expressing the partial dependencies among the TreeNet model response and the variable values were used to interpret their effects on tree recruitment. Those graphs reflect a typical relationship between the target $(\mathrm{Y})$ and any one predictor considering that all other variable effects are taken into account to arrive at a typical relationship, and that the graph $\mathrm{E}$ $\left(\mathrm{Y} \mid \mathrm{X}_{\mathrm{i}}\right)$ for a single predictor $\mathrm{X}_{\mathrm{i}}$, integrates out all other relevant predictors (Salford-Systems, 2017).

\subsection{Mapping tree recruitment proneness}

Once the statistical models that explain the susceptibility to tree recruitment were constructed, their outcomes were spatialized in two ways: For the whole rangelands area, the models were deployed over a $200 \mathrm{~m}$ regular grid of georeferenced points where the information of the main explaining variables was known. Similarly, for the afforested plots, in order to achieve a more detailed spatial resolution in those areas, another grid of points was generated and models deployed, herein with a regular spatial segregation of $5 \mathrm{~m}$.

The percentage of surface predicted as prone to tree recruitment was hence calculated separately for the whole rangelands and for the afforested areas. This was done to determine whether or not afforestations were carried out on places that already were naturally prone to tree recruitment. The three operative subprograms (S1: 1992-1999, S2: 2000-2006 and S3: 2007-2013) as well as the areas actually determined as afforested vs. those classified as delineation errors were independently analyzed.

\section{Results}

\subsection{Tree dynamics and characteristics of the afforestations}

An amount of 16,747 trees were determined as new, 47,058 as remaining and 12,803 as lost along the studied period (1956-2012) in the 800 sampled plots. Although the amounts indicate an increasing number of trees, their spatial distribution is not homogeneous, being lost and recruited trees quite spatially segregated, with the new ones mainly observed over marginal areas (Herguido et al., 2017).

Approximately 5600 afforestation events were performed during the analyzed subprograms, covering approximately 79,221 ha in the study area. From these, 47,129 ha correspond to the 3433 actions performed in dehesas or pasturelands (Fig. 1), being 3381 of them carried out with holm oak (Quercus ilex) and/or cork oak (Quercus suber) as the main tree species, which accounted to approximately 46,675 ha. Other less 
Table 1

Information about the total sampled area per subprogram of the First Afforestation of Agricultural Land program and the cartographic error estimated when delineating afforested surfaces.

\begin{tabular}{llll}
\hline Subprograms & Area (ha) & No. of plots & Error \%; ha \\
\hline $1992-1999$ & $34,198.33$ & 2337 & $6.98 ; 2387.04$ \\
$2000-2006$ & $8,884.65$ & 666 & $7.69 ; 683.22$ \\
$2007-2013$ & $3,591.66$ & 378 & $1.29 ; 46.33$ \\
\hline
\end{tabular}

frequent species used in combination with holm or cork oak, were Olea europaea, Pinus spp., Fraxinus spp., Celtis australis, Retama sphaerocarpa, Quercus faginea, Quercus pyrenaica, Arbutus unedo, Castanea sativa, Ceratonia silicua, Salix spp., Populus spp., Ulmus pumila, Prumus avium, Alnus glutinosa, Acer monspesulanum and Juglans regia. Afforestations considered for the study were those performed by planting pure holm or cork oak, along with those planted as combinations, among them or with any of the abovementioned species. Pure or mixed plantations that did not include holm nor cork oak were not considered.

The mean delineation error of the cartography of afforested plots estimated by reviewing the $10 \%$ of the SIGPAC afforested plots accounted to a $6.65 \%$ of the total sampled area. This error varied among subprograms and was much lower in the last one (Table 1).

\subsection{Results of the models and deployment on the whole rangelands area}

All the models performed showed a high fitness when forecasting the places prone or not prone to undergo natural tree recruitment (Table 2). Attending to the ROC AUC, the more accurate algorithm was Random Forest (RF), which showed an AUC of 0.95 for both the learn and test sample datasets. AUC of the TreeNet gradient boosting machine model (TN) was quite similar to that of RF (0.92); however, the misclassification rate obtained on the additional $5 \%$ test dataset was lower, only amounting to the $9.2 \%$ of the cases for both, presence and absence of tree recruitment. Multivariate Adaptive Regression Splines (MARS) showed the lower fitness, while still retrieved a high AUC $(0.85)$ and relatively low misclassification rates $(22 \%$ of the tree recruitment absences and $23 \%$ of the presences). The model ensemble showed misclassification rates of $12.8 \%$ for both, presences and absences using the $5 \%$ test set.

As showed in Table 3, TN and RF models involved the 15 variables selected by the TN-GLM method, while MARS only involved 7 among them. Attending to the relative importance of the variables, although they were differently ranked depending on the algorithm (Table 3), 6

Table 2

Model fitness parameters obtained with the different models: TreeNet gradient boosting machine (TN), Random Forest (RF), Multivariate Adaptive Regression Splines (MARS) and the model ensemble. Var $\mathrm{N}^{\mathrm{o}}$ : Number of variables included in the model; Threshold: optimal model output threshold to balance 1 (recruitment) and 0 (no recruitment) misclassification rates; AUC: Area Under the Receiver Operating Characteristic Curve of the learn, $25 \%$ test and $5 \%$ test datasets; Mis. Rate: misclassification rates of 0 and 1 obtained with the learn, $25 \%$ test and $5 \%$ test data sets.

\begin{tabular}{|c|c|c|c|c|c|}
\hline \multicolumn{2}{|c|}{ Model results } & \multirow{2}{*}{$\frac{\mathrm{TN}}{15}$} & \multirow{2}{*}{$\begin{array}{r}\mathrm{RF} \\
15\end{array}$} & \multirow{2}{*}{$\begin{array}{l}\text { MARS } \\
77\end{array}$} & \multirow{2}{*}{$\begin{array}{l}\text { Ensemble } \\
-\end{array}$} \\
\hline Var № & & & & & \\
\hline Threshold & & 0.510 & 0.560 & 0.459 & - \\
\hline (AUC) & Learn & 0.944 & 0.950 & 0.856 & - \\
\hline & Test (25\%) & 0.925 & 0.952 & 0.843 & - \\
\hline & Test (5\%) & 0.924 & 0.951 & 0.856 & - \\
\hline Mis. rate & 0 & 0.126 & 0.125 & 0.284 & - \\
\hline (Learn) & 1 & 0.123 & 0.115 & 0.175 & - \\
\hline Mis. rate & 0 & 0.148 & 0.119 & 0.251 & - \\
\hline test $(25 \%)$ & 1 & 0.142 & 0.116 & 0.236 & - \\
\hline Mis. rate & 0 & 0.092 & 0.111 & 0.217 & 0.128 \\
\hline test $(5 \%)$ & 1 & 0.092 & 0.109 & 0.232 & 0.128 \\
\hline
\end{tabular}

Table 3

Relative importance of the variables in each model. TN-GLM: TreeNet gradient boosting machine performed for variable selection (the first 15 variables), TN: TreeNet gradient boosting machine, RF: Random Forest and MARS: Multivariate Adaptive Regression Splines. Variable abbreviations are: Durban: Distance to urban areas, Droads: Distance to roads, TPI: standardized Topographic Position Index, AU 2009: Animal Units per municipality in 2009, Cattle 2009: Percentage of Animal Units corresponding to cattle in 2009, Drivers: Distance to water courses, mean $T^{\mathrm{a}}$ WQ: Mean temperature of the warmest quarter and Population 2006: Population density of the municipality in 2006. The top three variables per model are highlighted in bold.

\begin{tabular}{|c|c|c|c|c|}
\hline \multirow[t]{2}{*}{ Variable } & \multicolumn{4}{|c|}{ Relative importance score (\%) } \\
\hline & TN-GLM & $\mathrm{TN}$ & RF & MARS \\
\hline Tree cover (\%) & 100 & 96.93 & 100 & 100 \\
\hline Slope & 92.7 & 93.82 & 90.53 & 66.33 \\
\hline Shrub cover $(\%)$ & 81.23 & 74.58 & 54.29 & 65.80 \\
\hline Elevation & 73.21 & 75.2 & 12.31 & 62.52 \\
\hline Durban & 72.32 & 78.35 & 8.97 & - \\
\hline$X$ coordinate & 71.82 & 100 & 14.09 & - \\
\hline Droads & 71.73 & 75.44 & 6.16 & - \\
\hline TPI & 71.58 & 72.53 & 12.98 & - \\
\hline$Y$ coordinate & 70.94 & 92.63 & 9.94 & - \\
\hline AU 2009 & 68.88 & 77.64 & 16.75 & - \\
\hline Cattle 2009 & 65.59 & 80.46 & 30.4 & 99.63 \\
\hline Drivers & 65.13 & 69.77 & 5.37 & - \\
\hline Mean $T^{\beth}$ WQ & 63.19 & 58.74 & 22.74 & 88.43 \\
\hline Soil type & 58.62 & 64.03 & 15.1 & 60.84 \\
\hline Population 2006 & 55.9 & 67.92 & 8.04 & - \\
\hline
\end{tabular}

variables among all models were rated to the top three positions, i.e., percentage of tree canopy cover, slope, percentage of shrub cover, $x$ coordinate (latitude), proportion of cattle in AU and mean temperature of the warmest quarter.

Plots depicting the partial dependencies among the main predictors and the TreeNet model outcomes that reflect the proneness to tree recruitment (Fig. 3), indicated a clear positive relationship with the percentage of tree cover and the slope i.e., higher proneness to tree recruitment when tree cover or slope increase. Similarly, low shrub cover (below 40\%) was related with low proneness, being the contrary for higher shrub cover, particularly with values between $40-60 \%$. Livestock composition, expressed as cattle percentage, is highly related with livestock number, both influencing model outcomes in the sense that a high percentage of cattle (usually coinciding with a low number of Animal Units) relates with high proneness to recruitment, being the contrary for low cattle number, which usually corresponds with a high number of animals and low recruitment proneness. The geographical space, represented by the $\mathrm{x}$ and $\mathrm{y}$ coordinates as well as by other variables depicting spatial relations, as the distances to urban areas or to roads, also plays important roles in model outcomes, while rather fuzzy. In the same sense do the mean temperature of the warmest quarter, the only climatic variable incorporated on the top three using MARS.

When models were spatially deployed to the whole rangeland surface (Fig. 4), all the algorithms, as well as the model ensemble, provided similar results in terms of the general spatial pattern of tree recruitment proneness. Nevertheless, outstanding differences among them were detected in the total area accounted (Table 4): $22.88 \%$ of the whole rangelands in the case of TN, $6.72 \%$ for RF, $36.03 \%$ for MARS and $12.60 \%$ for the model ensemble.

\subsection{Model deployment on afforested plots}

Even though the three algorithms predicted a different percentage of the rangelands as prone to tree recruitment, they provided similar results when the two deployment spaces were compared among each model, i.e., the whole rangelands or just the afforested plots (Table 4). Thus, for all the models, there existed only slight differences, in 
a)

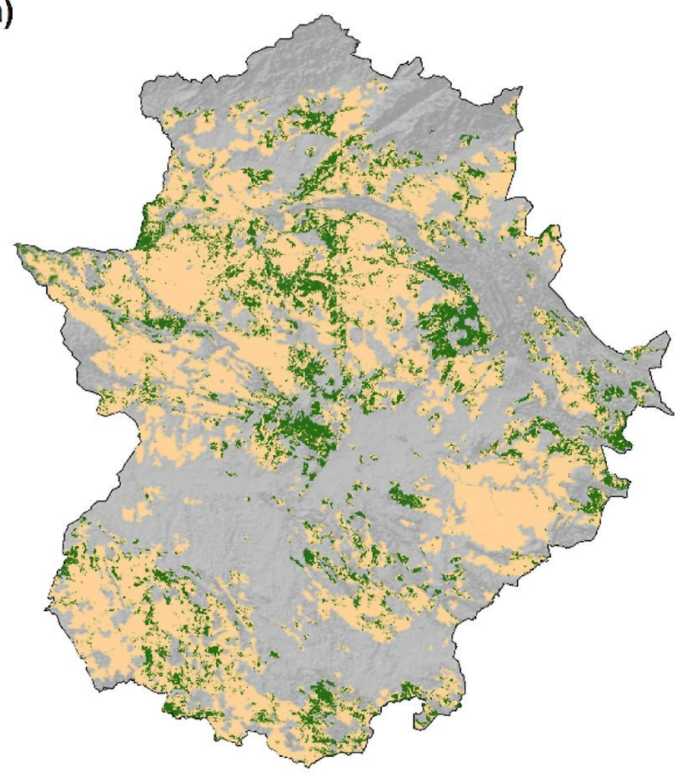

c)

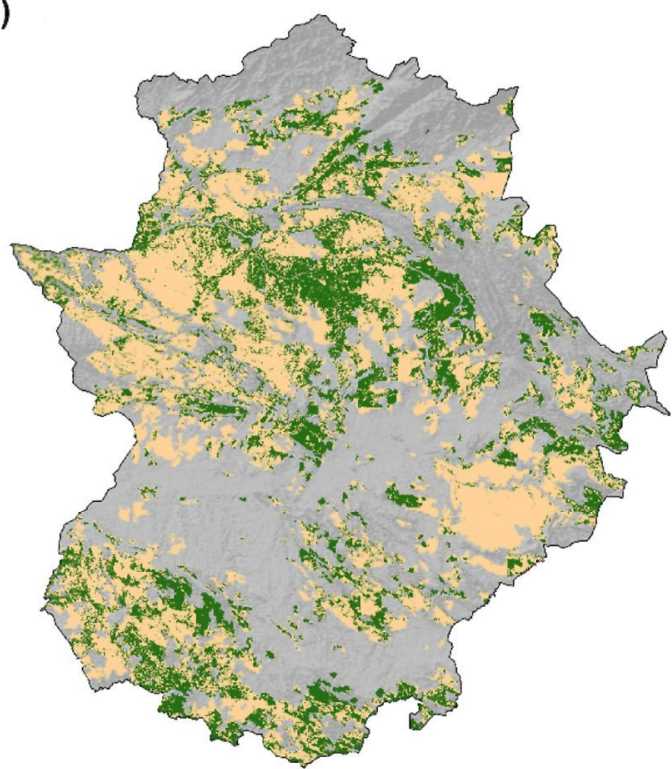

b)

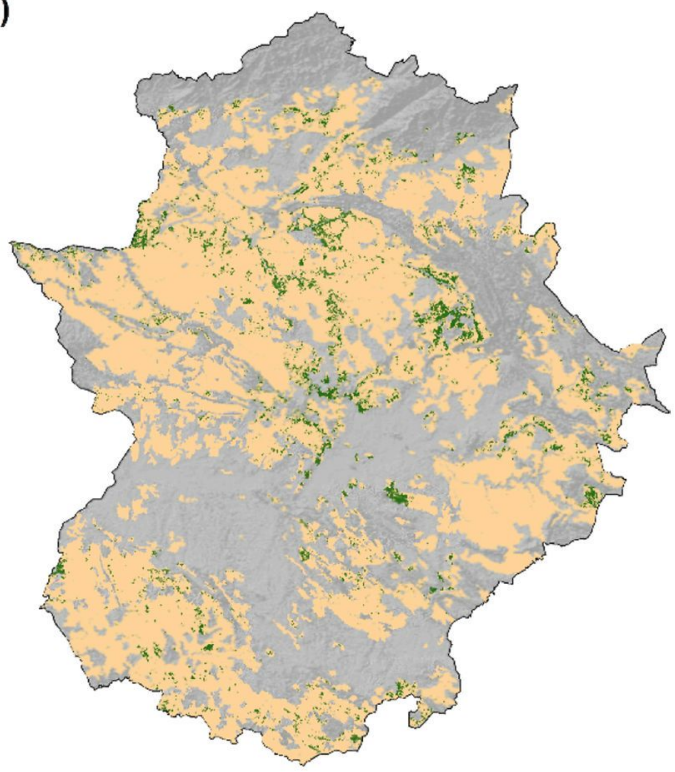

d)

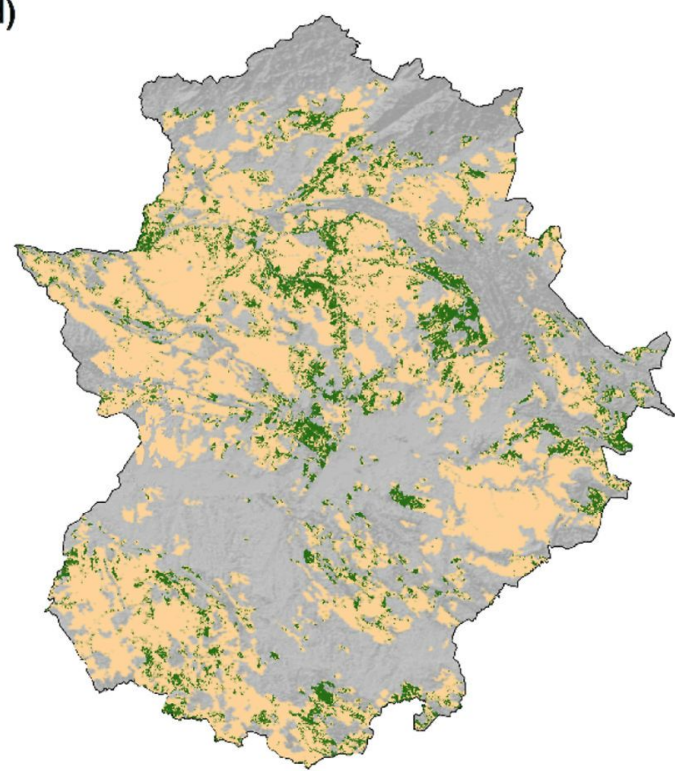

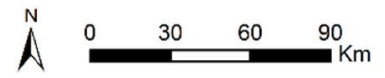

Not prone to tree recruitment

Prone to tree recruitment

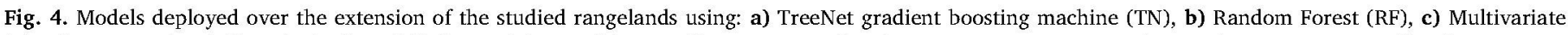

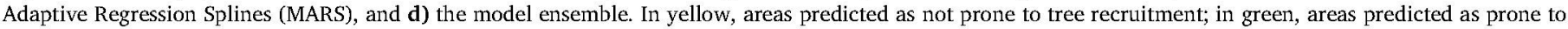
tree recruitment.

percentage amounts, between the areas predicted as prone to spontaneous tree recruitment in the whole rangelands and in the afforested lands. According with these results, afforestation activities barely discriminated between areas prone to undergo natural recruitment or not. When results were analyzed per operative subprograms, differences can be observed: plots afforested during the first period (1992-1999) showed higher percentage of their surface predicted as prone to tree recruitment than those performed during the other periods (2000-2006 and 2007-2013).

Results obtained when analyzing the $10 \%$ plots selected to check the cartographic reliability varied between the areas classified as truly afforested as compared to those that constituted delineation errors (Table 4). In general, incorrectly delineated areas showed higher percentage of surface prone to recruitment than true afforestations, especially in the first subprogram. Nevertheless, the area predicted as prone to tree recruitment of the later was still similar to that of the whole rangelands and afforestations.

\section{Discussion}

The different algorithms used differ in their statistical methods and they also produced models based on different variables, or giving the variables a different importance. However, even though differences were observed in the surface predicted as prone to tree recruitment among models, the spatial pattern obtained was similar for all of them, and so were other results (the proportion of the areas predicted as prone 
Table 4

Percentage of area predicted as prone to tree recruitment by the spatial models generated with TreeNet gradient boosting machine (TN), Random Forest (RF), Multivariate Adaptive Regression Splines (MARS) and the model ensemble, when models were deployed across the whole rangelands area of Extremadura, across all the afforested plots and across the $10 \%$ of afforestated plots checked for delineation errors: true afforestations and delineation errors.

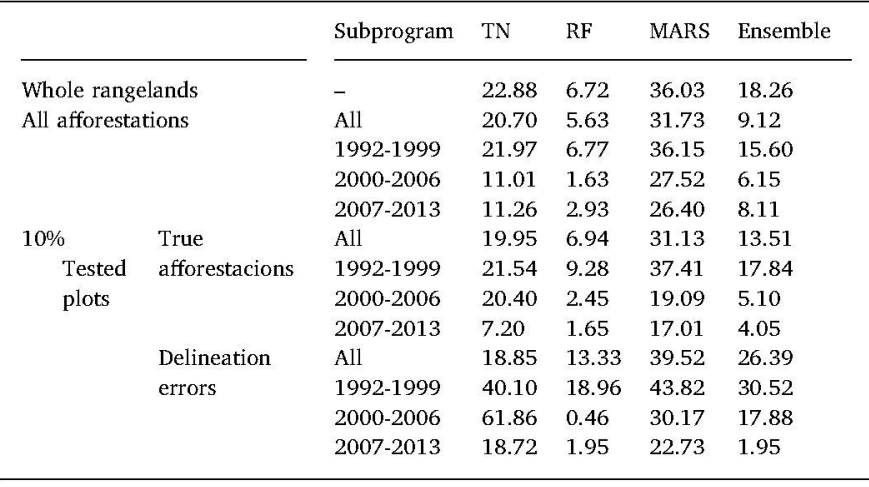

to tree recruitment for the whole rangelands, for the afforested areas and for the $10 \%$ of afforested plots checked for delineation errors). These similarities showed by the different algorithms make the obtained outcomes more consistent. Also, they allow to present a model ensemble in the form of a map of agreement, which could be considered to assess future programs.

Results obtained with the models built for the whole rangelands area in the studied region were consistent with those of a previous study performed at farm scale (Herguido et al., 2017), indicating that tree recruitment in dehesas and montados is highly restricted to marginal areas and can be correctly forecasted by predictive models. Those models are mainly influenced by topographic and land cover characteristics, but also by other socioeconomic, bioclimatic or geographical variables. Readily available topographical variables are wellknown to drive land uses (Veldkamp and Lambin, 2001), hence that it is not surprising that slope and elevation evidenced as some of the most important factors in the models. Livestock rearing and agricultural activities generally occur in the more exploitable and profitable areas, which in the rangelands of Extremadura mainly correspond to flat or gently undulated areas; being the steepest slopes usually prone to abandonment and constituting marginal areas. As a consequence tree and shrub density, as influenced by the intensity of land use, are also important when depicting and predicting tree recruitment in those rangelands.

When managing the marginal agricultural areas, two main approaches have been proposed: to prevent land abandonment or to favor land restoration (Pereira et al., 2005). During the last decades, due to globalization, low-input farming systems with diversified activities as dehesas or montados, have lost competitiveness in comparison to intensive farming (Jones et al., 2016). The socioeconomic trends in Europe make it difficult to prevent land abandonment in the long term. Even though the European Union makes an important effort through the Common Agricultural Policy to halt land abandonment, this is probably not enough at an individual level to attract young farmers or new residents to depopulated areas (Navarro and Pereira, 2012). Thus, land restoration might be a more realistic management choice in some areas. Rewilding, which implies land restoration and reduction of human control over the landscapes (Gillson et al., 2011), is also considered to improve some ecosystems services. Nonetheless, at a landscape scale, both strategies, maintaining extensive farming and rewilding, should be used in a spatially and functionally complementary way (Navarro and Pereira, 2012).

Afforesting and reforesting, when well done and with the correct species, can be a quick and straightforward way to accomplish forest restoration. Besides, this type of measures also favor ecosystem services such as carbon sequestration (Jandl et al., 2007), hence contributing to mitigate climate change (Zomer et al., 2008). On the other hand, passive forest regeneration through secondary succession represents an important percentage of the total forests recovery worldwide, being in the past even higher than active restoration (Rey Benayas and Bullock, 2012). Even though passive restoration has the advantage of being cheap, it might present problems and some actions might be needed. In some Mediterranean areas, for example, succession can be arrested by recurrent fires (Acácio et al., 2007) and the ecosystem stay in an undesirable shrub-encroached state in which biomass accumulation increases the fire risk, so that, in those cases, shrub clearing could be necessary to recover forests. Besides, woodland recovery can be slow, especially in low productive environments such as the Extremenian rangelands (Rey Benayas and Bullock, 2012). Furthermore, seed banks may be depleted due to long-term disturbances, so that planting woodland islets could be justified as an action to accelerate woodland recovery (Rey Benayas et al., 2008), letting the rest of the areas to selfrecovering.

In the case of the studied rangelands, once all the afforestation between 1992 and 2013 were analyzed, the results evidenced that those actions were frequently done in areas that, in fact, were already prone to passive restoration through natural tree regeneration. Thus, those areas did not specifically targeted neither of the previously discussed purposes: to restore areas for rewilding or to favor tree recruitment in the more intensively used areas, where there is a lack of trees or of losing them.

Particularly during the first subprogram period (1992-1999), results suggest that afforestation events did not discriminate areas prone to natural tree recruitment in a high percentage of cases. As compared to this period, data available for the last two subprograms (2000-2006 and 2007-2013) indicated a better discrimination of those areas. However, our results show that the proportion of afforested area modeled as prone to tree recruitment in those periods is only slightly lower than what models predicted for the whole rangelands of Extremadura. This data gains relevance if it is considered that the amount of area afforested during the first subprogram is much higher than the sum of it during the last two.

Regarding the important role that tree recruitment plays on the sustainability of dehesas, these afforestation actions might not constitute a proper solution for several reasons. Landowners are typically willing to perform afforestations only in the marginal lands. This is because the main areas of the farms are more profitable and managers are usually unwilling to set them aside from production for such a long period as the subsidies demand. Thus, the more exploited areas, that usually undergo the lower tree recruitment and higher tree loss (Herguido et al., 2017; Herguido Sevillano, 2017), are barely benefiting from the implementation of the afforestation programs analyzed in this study. Commonly, those areas also show improper age structures of the tree layer (Pulido et al., 2001). Besides the described fact of having been performed in incorrect spatial contexts, due to regulatory issues, afforestations require a minimum density of planted trees much higher than the typical tree density of a dehesa. Moreover, cutting trees is not allowed without permission with the current regulations and might remain forbidden in the future. In consequence, tree clearing on afforested areas in order to reach appropriate tree densities would likely to be not possible.

From the foregoing, it could be deduced that restoration efforts in not-marginal places should be focused on favoring a spatially equilibrated tree recruitment pattern that guarantees adequate tree densities for the future (Herguido Sevillano et al., 2017; Gibbons et al., 2008). This should be enough to replace the decaying or already disappeared trees. Since the main threads to the establishment of new trees are reported to be predation over seed, seedlings and saplings, protection of individual plants at these stages in selected places could improve tree recruitment. Leverkus et al. (2015) found that habitat complexity and 
individual protectors in sowed acorns significantly increased the success of land restoration after fires. In this direction, besides afforestation funds, the Forest Plan of Extremadura also considers aids aimed at tree densification by planting Holm and Cork oak in combination with the protection of naturally regenerated trees. Nevertheless, since the requirements of these aids were more restrictive and the funding amounts lower, owners usually preferred to apply for afforestation aids. In consequence, between 1994 and 2000 , only $12.4 \%$ (about 7500 ha) of the applications were devoted to tree densification, being $87.6 \%$ done to afforestation (Balbuena Gutiérrez and Doncel Pérez, 2001).

Whilst the above-mentioned funds for densification and saplings protection in dehesas lacked success because they were not attractive enough for farmers, the Afforestation of Agricultural Land program was not specifically designed to accomplish for the dehesa requirements. Consequently, it was applied without a properly designed plan that, additionally, up to the present, lack from enough monitoring over its long-term consequences and success rates (Campos et al., 2003).

More recently, other specific aids have been implemented to improve tree recruitment rates in dehesas. Although not analyzed in this study, two calls for grants were made in 2013 and 2014, and another one announced in 2017. These aids take into account the specific characteristics of the dehesas and do not require the target areas to be excluded from husbandry.

On the understanding that the implementation of measures, resources and efforts should be focused to the areas where tree recruitment really lack and do not exhibit a potential to be naturally reforested, the models developed herein could be useful as a tool to spatially asses and drive the implementation of afforestation policies and measures.

\section{Conclusions}

Data mining techniques are suitable to develop spatial models of vegetation dynamics. The models developed in the study showed a high performance when predicting areas that undergo natural tree regeneration in the rangelands of Extremadura. Tree recruitment was mainly occurring in the marginal areas, generally characterized by the existence of steep slopes, encroached by shrubs and already presenting a high tree density. When the results of tree recruitment models were compared with the afforestations performed along three subprogram periods of the EU Afforestation of Agricultural Land Program, it was found that afforestation actions barely discriminated those areas modeled as already prone to natural tree regeneration.

We conclude that spatial models with the algorithms used herein could be useful for policy and decision making aimed at assessing the implementation of afforestation measures and the selection of the more adequate locations. This could improve the cost-effectiveness of the programs, and the efforts to be concentrated on the less favorable areas to natural tree recruitment.

\section{Acknowledgments}

This study was funded by project AMID: CGL2011-23361 and E.H. was supported by a FPI grant (BES-2012-059249), both from the Spanish Ministry of Economy and Competitiveness (MINECO). We also thank the Extremenian Administration for providing information about afforestations performed in Extremadura under the First Afforestation of Agricultural Land Program. Finally, we thank the anonymous referees who helped to improve the manuscript with their suggestions.

\section{Appendix A. Supplementary data}

Supplementary material related to this article can be found, in the online version, at doi:https://doi.org/10.1016/j.landusepol.2018.06. 054.

\section{References}

Acácio, V., Holmgren, M., Jansen, P.A., Schrotter, O., 2007. Multiple recruitment limitation causes arrested succession in Mediterranean Cork Oak systems. Ecosystems $10,1220-1230$.

Baddeley, A.J., Turner, R., 2005. Spatstat: an $\mathrm{r}$ package for analyzing spatial point pattens. J. Stat. Softw. 12, 1-42.

Baddeley, A., Rubak, E., Turner, R., 2015. Spatial Point Patterns. Methodology and Applications with R. Chapman and Hall/CRC Press, London.

Balbuena Gutiérrez, E., Doncel Pérez, E., 2001. Estado de las densificaciones de arbolado realizadas con encina (Quercus ilex L.) y alcornoque (Quercus suber L.) en Extremadura en el periodo 1994-2000. Montes 65, 19-30.

Beven, K.J., Kirkby, M.J., 1979. A physically based, variable contributing area model of basin hydrology / Un modèle à base physique de zone d'appel variable de l'hydrologie du bassin versant. Hydrol. Sci. Bull. 24, 43-69.

Breiman, L., 2001. Random forests. Mach. Learn. 45, 5-32.

Campos, P. Martín, D., Montero, G., 2003. Economía de la reforestación del alcornoque y de la regeneración natural del alcornocal. In: Pulido, F. (Ed.), La Gestión Forestal De Las Dehesas. Historia, Ecología, Selvicultura y Economía, pp. 107-151.

Carmona, C.P., Azcárate, F.M., Oteros-Rozas, E., González, J.A., Peco, B., 2013. Assessing the effects of seasonal grazing on holm oak regeneration: implications for the conservation of Mediterranean dehesas. Biol. Conserv. 159, 240-247.

R. Core Team, 2015. R: A Language and Environment for Statistical Computing. R Foundation for Statistical Computing, Vienna, Austria.

Costa, A., Madeira, M., Plieninger, T., 2014. Cork oak woodlands patchiness: a signature of imminent deforestation? Appl. Geogr. 54, 18-26.

den Herder, M., Moreno, G., Mosquera-Losada, R.M., Palma, J.H.N., Sidiropoulou, A., Santiago Freijanes, J.J., Crous-Duran, J., Paulo, J.A., Tomé, M., Pantera, A. Papanastasis, V.P., Mantzanas, K., Pachana, P., Papadopoulos, A., Plieninger, T., Burgess, P.J., 2017. Current extent and stratification of agroforestry in the European Union. Agriculture. Ecosyst. Environ. 241, 121-132.

Diaz, M., Campos, P., Pulido, F., 1997. The Spanish dehesas: a diversity in land-use and wildlife. In: Pain, D., Pienkowski, M. (Eds.), Farming and Birds in Europe. Academic Press, London, pp. 178-209.

Dormann, C.F., Elith. J., Bacher, S., Buchmann. C., Carl, G., Carré, G., Marquéz, J.R.G. Gruber, B., Lafourcade, B., Leitão, P.J., Münkemüller, T., McClean, C., Osborne, P.E., Reineking, B., Schröder, B., Skidmore, A.K., Zurell, D., Lautenbach, S., 2013. Collinearity: a review of methods to deal with it and a simulation study evaluating their performance. Ecography 36, 27-46.

Friedman, J.H., 1991. Multivariate adaptive regression splines. Ann. Stat. 19, 1-67.

Gibbons, P., Lindenmayer, D.B., Fischer, J., Manning, A.D., Weinberg, A., Seddon, J. Ryan, P., Barrett, G., 2008. The future of scattered trees in agricultural landscapes. Conserv. Biol. 22, 1309-1319.

Gillson, L., Ladle, R.J., Araújo, M.B., 2011. Baselines, Patterns and Process, Conservation Biogeography. John Wiley \& Sons, Ltd, pp. 31-44.

Godinho, S., Guiomar, N., Machado, R., Santos, P., Sá-Sousa, P., Fernandes, J.P., Neves, N., Pinto-Correia, T., 2014. Assessment of environment, land management, and spatial variables on recent changes in montado land cover in southern Portugal. Agrofor. Syst. 90, 177-192.

Gómez Amelia, D., 1985. La Penillanura Extremeña: Estudio Geomorfológico. Universidad de Extremadura, Cáceres, Spain.

Herguido, E., Lavado Contador, J.F., Gómez Gutiérrez, A., Schnabel, S., 2017. Modeling Tree loss vs. Tree recruitment processes in SW iberian rangelands as influenced by topography and land use and management. Land Degrad. Dev. 28, 1652-1664.

Herguido Sevillano, E., Lavado Contador, J.F., Pulido, M., Schnabel, S., 2017. Spatial patterns of lost and remaining trees in the iberian wooded rangelands. Appl. Geogr. 87, 170-183.

Hijmans, R.J., Cameron, S.E., Parra, J.L., Jones, P.G., Jarvis, A., 2005. Very high resolution interpolated climate surfaces for global land areas. Int. J. Climatol. 25, 1965-1978.

Jandl, R., Lindner, M., Vesterdal, L., Bauwens, B., Baritz, R., Hagedorn, F., Johnson, D.W. Minkkinen, K., Byrne, K.A., 2007. How strongly can forest management influence soil carbon sequestration? Geoderma 137, 253-268.

Jones, N., Fleskens, L., Stroosnijder, L., 2016. Targeting the impact of agri-environmental policy - future scenarios in two less favored areas in Portugal. J. Environ. Manage. $181,805-816$.

Leverkus, A.B., Rojo, M., Castro, J., 2015. Habitat complexity and individual acom protectors enhance the post-fire restoration of oak forests via seed sowing. Ecol. Eng. 83, 276-280.

López-Sánchez, A., Perea, R., Dirzo, R., Roig, S., 2016. Livestock vs. Wild ungulate management in the conservation of Mediterranean dehesas: implications for oak regeneration. For. Ecol. Manage. 362, 99-106.

Moreno, G., Pulido, F.J., 2009. The functioning, management and persistence of dehesas. In: Rigueiro-Rodróguez, A., McAdam, J., Mosquera-Losada, M. (Eds.), Agroforestry in Europe. Springer, Netherlands, pp. 127-160.

Navarro, L.M., Pereira, H.M., 2012. Rewilding abandoned landscapes in Europe Ecosystems 15, 900-912.

Pereira, E., Queiroz, C., Pereira, H.M., Vicente, L., 2005. Ecosystem services and human well-being: a participatory study in a mountain community in Portugal. Ecol. Soc. 10

Plieninger, T., Pulido, F.J., Konold, W., 2003. Effects of land-use history on size structure of holm oak stands in Spanish dehesas: implications for conservation and restoration. Environ. Conserv. 30, 61-70.

Pulido, F., Picardo, Á., 2010. Libro verde de la dehesa, Documento para el debate hacia una estrategia ibérica de gestión. Available from:. (Accesed November 2017). https://www.eweb.unex.es/eweb/accionporladehesa/documentos/libro_verde_ 
dehesa.pdf.

Pulido, F.J., Díaz, M., Hidalgo de Trucios, S.J., 2001. Size structure and regeneration of Spanish holm oak Quercus ilex forests and dehesas: effects of agroforestry use on their long-term sustainability. For. Ecol. Manage. 146, 1-13.

Rey Benayas, J.M., Bullock, J.M., 2012. Restoration of biodiversity and ecosystem services on agricultural Land. Ecosystems $15,883-899$.

Rey Benayas, J.M., Bullock, J.M., Newton, A.C., 2008. Creating woodland islets to reconcile ecological restoration, conservation, and agricultural land use. Front. Ecol. Environ. 6, 329-336.

Ruiz, F., López, G., Toval, G., Alejano, R., 2008. Selvicultura de Eucalyptus globulus Labill. In: Serrada, R., Montero, G., Reque Kílchenmann, J.A. (Eds.), Compendio de Selvicultura Aplicada En España. Instituto Nacional de Investigación y Tecnología Agraria y Alimentaria (INIA), Madrid, pp. 118-154.

Salford-Systems, 2017. Introducing TreeNet gradient boosting machine. SPM Users Guide. Available from. http://media.salford-systems.com/pdf/spm8/TreeNet_ Documentation_v_8_2.pdf (Acessed November 2017).

Sánchez-González, M., Gea-Izquierdo, G., Pulido, F., Acácio, V., McCreary, D., Cañellas, I., 2015. Restoration of Open Oak Woodlands in Mediterranean ecosystems of Western Iberia and California. In: Stanturf, J.A. (Ed.), Restoration of Boreal and Temperate Forests, second edition. CRC Press, pp. 377-400.

Schnabel, S., Pulido-Fernández, M., Lavado-Contador, J.F., 2013. Soil water repellency in rangelands of Extremadura (Spain) and its relationship with land management. CATENA 103, 53-61.

Seni, G., Elder, J.F., 2010. Ensemble methods in data mining: improving accuracy through combining predictions. Synth. Lect. Data Min. Knowl. Discov. 2 (1), 1-126.
Toval, G., 1999. Repoblaciones forestales. In: Madrigal, A. (Ed.), 150 años de Aportaciones de Los Ingenieros de Montes. Fundación Conde del Valle de Salazar, Madrid, pp. 313-339.

Uthes, S., Matzdorf, B., Müller, K., Kaechele, H., 2010. Spatial targeting of Agri-environmental measures: cost-effectiveness and distributional consequences. Environ. Manage. 46, 494-509.

Vadell, E., de-Miguel, S., Pemán, J., 2016. Large-scale reforestation and afforestation policy in Spain: a historical review of its underlying ecological, socioeconomic and political dynamics. Land Use Policy 55, 37-48.

Veldkamp, A., Lambin, E.F., 2001. Predicting land-use change. Agric. Ecosyst. Environ. $85,1-6$

Verburg, P.H., Rounsevell, M.D.A., Veldkamp, A., 2006. Scenario-based studies of future land use in Europe. Agric. Ecosyst. Environ. 114, 1-6.

Weiss, A., 2001. Topographic Position and Landforms Analysis (Conference Poster).

Zaragozí, B., Rabasa, A., Rodríguez-Sala, J.J., Navarro, J.T., Belda, A., Ramón, A., 2012 Modelling farmland abandonment: a study combining GIS and data mining techniques. Agric. Ecosyst. Environ. 155, 124-132.

Zevenbergen, L.W., Thorne, C.R., 1987. Quantitative analysis of land surface topography. Earth Surf. Processes Landforms 12, 47-56.

Zomer, R. Bossio, D., Trabucco, A., Yuanjie, L., Gupta, D., Singh, V., 2007. Trees and Water: Smallholder Agroforestry on Irrigated Lands in Northern India. International Water Management Institute, Colombo, Sri Lanka.

Zomer, R.J., Trabucco, A., Bossio, D.A., Verchot, L.V., 2008. Climate change mitigation: spatial analysis of global land suitability for clean development mechanism afforestation and reforestation. Agric. Ecosyst. Environ. 126, 67-80. 